\title{
Seminário como estratégia pedagógica para o estudo das ferramentas de suporte ao Teste de Software
}

\author{
Naiara da Encarnação Neves ${ }^{1}$, Graci Bispo da Encarnação ${ }^{2}$ \\ ${ }^{1}$ Serviço Nacional de Aprendizagem Industrial - Campus Integrado de Manufatura e \\ Tecnologia (SENAI CIMATEC) - Salvador - BA - Brasil \\ ${ }^{2}$ Programa de Pós-Graduação em Educação e Contemporaneidade (PPGEduC) - \\ Universidade do Estado da Bahia (UNEB) - Salvador, BA - Brasil \\ naiara.nevesdfieb.org.br, gracibe@gmail.com
}

\begin{abstract}
Software Testing is one of its activities that contributes to improving software quality and, in this context, it is necessary to learn about Software Testing. This article describes an experience during the Software Testing Support Tools Seminar with Students in the Technical Systems Development and Informatics Course of a private education institution in Salvador / Bahia. To collect data, use techniques such as observation, semi-structured interview and questionnaire. As activities contributed to the improvement of know-how in Software Testing.
\end{abstract}

Resumo. O Teste de Software é uma das atividades que buscam contribuir para a melhoria da qualidade do software e, neste contexto há a necessidade de aprender sobre Teste de Software. Este artigo descreve a experiência durante o Seminário de Ferramentas de Suporte ao Teste de Software com os estudantes do Curso Técnico em Desenvolvimento de Sistemas e em Informática de uma instituição de ensino particular em Salvador/Bahia. Para a coleta de dados utilizou-se técnicas como: observação, entrevista semiestruturada e questionário. As atividades contribuíram para o aprimoramento do know-how em Testes de Software.

\section{Introdução}

Este artigo suscita reflexões referentes à experiência pedagógica em que o Seminário foi adotado como estratégia para o estudo das ferramentas de Teste de Software, no Serviço Nacional de Aprendizagem Industrial - Centro Integrado de Manufatura e Tecnologia (SENAI-CIMATEC), com os estudantes dos cursos Técnico em Desenvolvimento de Sistemas, na disciplina Testes de Sistemas e no curso Técnico em Informática, na disciplina Qualidade de Sistemas II no primeiro semestre de 2019.

A ementa das duas disciplinas propõe apresentar aos docentes os conceitos básicos, normas e modelos de qualidade do processo e do produto de software, assim como apresentar os conceitos de verificação e validação de software e os princípios, métodos, técnicas e ferramentas de apoio às atividades de Teste de Software.

Segundo Pressman (2006), a atividade de teste é um dos elementos críticos da garantia da qualidade de software e pode assumir até quarenta por cento do esforço 
VIII Congresso Brasileiro de Informática na Educação (CBIE 2019)

Anais do XXV Workshop de Informática na Escola (WIE 2019)

gasto em seu desenvolvimento. No entanto, a atividade de teste de software revela-se como uma atividade estruturada e sistemática baseada em técnicas, ferramentas e processos formais.

Atualmente os paradigmas de ensino e aprendizagem sofreram transformações significativas, o que permitiu evoluir, por uma parte, de modelos educativos centrados no ensino, a modelos dirigidos à aprendizagem, e por outra, à mudança nos perfis de professores e estudantes. Nesse sentido, os novos modelos educativos demandam que os docentes transformem seu papel de expositores do conhecimento ao de monitores da aprendizagem, e os estudantes de meros espectadores do processo de ensino, ao de integrantes participativos e críticos na construção de seu próprio conhecimento.

A partir desse contexto, alguns questionamentos surgiram sobre o tema, tais como: Qual a melhor forma de ensinar teste de software? Quais as ferramentas podem ser exploradas? Como os estudantes podem conhecer os profissionais da área? Estas e as questões apresentadas em [Benitti e Albano 2012] motivaram o desenvolvimento desta pesquisa, gerando a suposição de que o Seminário poderia ser uma excelente estratégia nas disciplinas.

\section{Métodos}

Esta pesquisa adotou um paradigma misto, com técnicas exploratórias de natureza qualitativa complementadas com técnicas quantitativas. Assim, na direção de investigar o Seminário como estratégia pedagógica, foram utilizadas diferentes técnicas de coleta de dados como observação, entrevista semiestruturada e questionário.Participaram do estudo 42 alunos de três turmas dos três turnos (matutino, vespertino e noturno).

Diante da metodologia alemã TheoPrax adotada na instituição para todos os estudantes dos cursos técnicos, a qual estimula a motivação para o aprendizado por meio de projetos e problemas reais de empresa, optou-se por permitir aos estudantes explorarem as ferramentas de Teste de Software para complementar e garantir a qualidade do software desenvolvido no Projeto Final de Curso (PFC).

O Seminário consiste numa apresentação oral dos alunos, normalmente divididos em equipes, de um conteúdo pré-estabelecido. Segundo Veiga (2008), o seminário é uma técnica de ensino socializado, na qual os alunos se agrupam com o objetivo de estudar, investigar e discutir um ou mais temas, sob a direção do professor. A participação do professor é fundamental, pois age para coordenar o processo conforme as observações de Veiga (2008).

No geral, as ferramentas estudadas são usadas como ferramentas de execução, preparação de dados de teste, gerenciamento de requisitos, escrita de casos de teste, procedimentos de teste, scripts de teste automatizados, resultados de testes, gestão dos defeitos ou até mesmo para relatórios e monitoramento da execução dos testes. As ferramentas propostas foram: Mantis Bug Tracker, Testlink, Sonar Qube, JUnit, Selenium WebDriver, Jenkins, Moq. Todas ferramentas foram software livre. De acordo com a definição de Richard Stallman: é qualquer programa de computador que pode ser usado, copiado, estudado, modificado e redistribuído sem nenhuma restrição, ou seja, liberdade e não gratuidade. 
VIII Congresso Brasileiro de Informática na Educação (CBIE 2019)

Anais do XXV Workshop de Informática na Escola (WIE 2019)

O Seminário foi aberto ao público externo. Dos três turnos, a maior quantidade de participantes foi no turno noturno, principalmente pelos profissionais da área de qualidade de software demonstrarem interesse em participar bem como disponibilidade após a divulgação do Seminário na comunidade de profissionais de teste, o Grupo de Testadores da Bahia (GTS-BA). Desta forma, surgiu a necessidade de criar uma página na plataforma online de eventos Sympla (https:/www.sympla.com.br/seminarioferramentas-de-suporte-ao-teste-de-software 537151) para gerenciar melhor os participantes, onde cinquenta e sete profissionais realizaram inscrição na plataforma.

A primeira etapa do trabalho proposto consistiu na construção e publicação de um vídeo no YouTube apresentando desde a instalação até um breve uso da ferramenta a ser compartilhado durante o Seminário através de uma playlist por turma. Uma playlist é uma coleção de vídeos, onde é possível catalogar vídeos e compartilhar o link. No Seminário, essa playlist foi compartilhada através de um código impresso no folder dentro de uma pasta para todos os participantes conforme Figura 1.

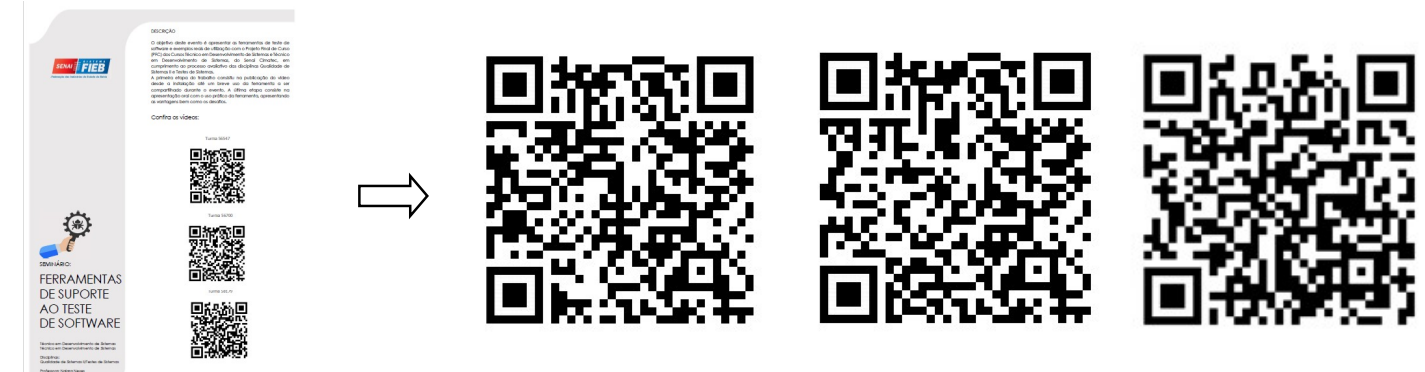

Figura 1. Folder e QR Code por turma contendo a playlist com os vídeos

A segunda etapa consistiu na apresentação oral propriamente dita de todo estudo realizado na ferramenta, incluindo vantagens e desafios identificados no uso da ferramenta por cada equipe. Destaca-se a programação realizada no turno noturno: No dia 27/05 foram apresentadas as ferramentas bem como o relato de experiência de uma analista de teste sobre sua carreira com ênfase em projetos internacionais e testes automatizados. No dia 30/05 foram apresentadas as demais ferramentas, o relato de experiência de um analista de teste e bate papo com os profissionais presentes.

Para subsidiar o artigo, fez-se necessário a realização de uma coleta de dados. A ferramenta escolhida para esta finalidade foi o questionário. As informações foram coletadas com a permissão dos participantes e as suas identificações foram anônimas. $O$ público-alvo foi definido como os estudantes que cursaram a disciplina e participaram do Seminário, os quais foram convidados através do link do questionário no Google Sala de Aula, ferramenta de comunicação adotada pela docente ao longo das disciplinas.

\section{Resultados e Discussões}

O questionário foi composto por dez questões relacionadas ao desenvolvimento da atividade, o qual foi construído e acessado de forma on-line e ficou disponível de 14 de junho de 2019 até dia 14 de julho de 2019. Nesta seção será apresentada uma breve análise dos dados obtidos e uma discussão sobre as respostas obtidas. Ao total, foram registradas 32 respostas. 
Quando questionados qual era avaliação sobre iniciativa em realizar o Seminário, 30 respostas foram positivas. Sobre a questão que aborda se o Seminário cumpriu com os objetivos traçados, a maioria dos respondentes ( 29 respostas) respondeu positivamente. $\mathrm{O}$ uso efetivo das ferramentas aliadas ao PFC tornou-se uma espécie de diário, um estudante relatou: "Não estávamos conseguindo configurar na sexta-feira, mas sábado estudamos mais e conseguimos resolver a configuração. No domingo, ajustamos o projeto. Na segunda-feira, a ferramenta identificou alguns bugs e fomos corrigindo.".

Uma contribuição que pode ser citada é a constatação da relevância e benefícios resultante de explorar as ferramentas de suporte ao teste de software de forma autônoma, tal como identificar os benefícios e riscos da automação de testes e classificar as ferramentas de teste de acordo com a sua finalidade e as atividades de teste que elas suportam. Foi possível observar no contexto da sala de aula e fora dela como os alunos buscavam sanar dúvidas e integrar com efetividade a ferramenta ao PFC, inclusive alguns relatavam que gostaram tanto que já estavam utilizando no estágio e/ou local de trabalho.

A Tabela 1, a seguir, apresenta algumas respostas quando questionados sobre o que mais gostou no Seminário.

Tabela 1. Respostas sobre "O que você mais gostou no Seminário? "

a presença de diversos testadores e profissionais desta área

conhecer ferramentas de teste

Troca de conhecimentos

Da participação de profissionais da área, da proposta de aplicar a ferramenta e não ficar apenas na teoria, etc

Todo o desempenho da turma, professora e todos o seus convidados em estarem dispostos a aprender e contribuir para um ambiente educacional, bem como para vidas de cada um. Acredito que todos saíram com uma penca de assuntos e ferramentas para utilizarem em qualquer nível de atuação. Estamos trabalhando para melhorar e acredito que tudo que foi demonstrado nas apresentações foi um espelho do grande esforço que todo ser tiveram para melhorar!

Pude ter contato com profissionais da área de software que compartilharam suas experiências e forneceram dicas para os alunos crescerem como profissionais.

Ter que ser auto-didata.

Da habilidade desenvolvida por mim, principalmente, de conseguir passar o conteúdo construído por mim de uma forma satisfatória para a plateia

Ouvir dos profissionais suas experiências.

A autonomia exercida pelos alunos é um ponto crucial para a busca pelo conhecimento e isso é fundamental para o desenvolvimento do aluno como pessoa e como profissional.

A investigação e os relatos acima mostraram que o uso do Seminário teve efeitos positivos no engajamento dos alunos: estimulou a exposição, o debate e o ensino com pesquisa. Para os estudantes, além do aprendizado, eles foram instigados a explorar a 
VIII Congresso Brasileiro de Informática na Educação (CBIE 2019)

Anais do XXV Workshop de Informática na Escola (WIE 2019)

ferramenta e a professora figurou como consultora de eventuais dúvidas, registrando pontos fortes e fracos de cada ferramenta e estimulando o uso por todos os integrantes da equipe.

A oportunidade do contato com os profissionais da área de Teste de Software relatando sua carreira nas empresas e experiência com os projetos, inclusive com o uso das ferramentas estudadas foi um ponto destacado e bem comentado pelos próprios estudantes, além disso os profissionais que participaram do Seminário unanimemente expressaram a satisfação em participar em outra edição bem como indicariam a outra (s) pessoa (s) a participação quando foram questionados.

\section{Conclusões}

Através das apresentações dos Seminários podemos concluir que os objetivos deste trabalho foram alcançados, inclusive pelas discussões e respostas coletadas sobre diversos aspectos das ferramentas estudadas, compreendendo claramente algumas ligações relevantes entre teoria e prática.

Este estudo analisou a efetividade do Seminário para estimular o engajamento entre estudantes, melhorar a prática em Teste de Software e explorar as ferramentas estudadas no semestre. A investigação mostrou que o uso do Seminário teve efeitos positivos no engajamento dos alunos. Os estudantes que apresentaram oralmente bastante domínio sobre a ferramenta estudada, também foram os que mais sanaram dúvidas ao longo das aulas e mais receberam elogios dos profissionais nas apresentações.

A partir deste estudo, o Seminário revela-se como uma estratégia para o alcance dos objetivos educacionais, inclusive para o estudo das ferramentas de Teste de Software, não somente de conhecimento técnico, mas incremento da formação intelectual e interativa do estudante.

\section{Referências}

Albano, E. L. (2012). Planejamento, Construção e Avaliação de Objetos de Aprendizagem para Apoio ao Ensino de Teste de Software. Qualificação de Mestrado - Universidade do Vale do Itajaí, Itajaí, 2012.

Benitti, F. B. V. ; Albano, E. L. . Teste de Software: o que e como é ensinado?. In: WEI XX Workshop sobre Educação em Computação, 2012, Curitiba-PR. WEI - XX Workshop sobre Educação em Computação, 2012.

Benitti, F.B.V. Avaliando Objetos de Aprendizagem para o Ensino de Teste de Software. In: Nuevas Ideas en Informática Educativa TISE, 2015, Chile.

Gil, A. C. (1999) Métodos e Técnicas de Pesquisa Social. São Paulo: Atlas.

Pressman, Roger S. Engenharia de software. São Paulo: Makron Books, 2006.

Somerville, I. Engenharia de Software. 8. ed. São Paulo: Addison-Wesley Brasil, 2007.

Veiga, I. P. A. O seminário como técnica de ensino socializado. (2008). In: VEIGA, Ilma. Passos Alencastro (Org). Técnicas de ensino: por que não? 19a ed. Campinas: Papirus. 